\title{
Epsilon-aminocaproic acid therapy in ulcerative colitis
}

\author{
R. H. SALTER ${ }^{1}$ AND A. E. READ \\ From the Department of Medicine, Bristol Royal Infirmary
}

SUMMARY On the supposition that excessive fibrinolysis at the rectal mucosal level may $\stackrel{\circ}{-}$ contribute to the pathogenesis of ulcerative colitis, 11 patients with this condition, in whom $\subseteq$ rectal bleeding was the predominant feature, were given a course of epsilon-aminocaproic acid therapy. Six patients responded dramatically to this treatment, there was a partial response in two, no effect in two others, and one patient found it necessary to discontinue the treatment after 48 hours because of the severity of side effects.

Rectal bleeding and diarrhoea are the cardinal symptoms of ulcerative colitis (Goligher, de Dombal, Watts, and Watkinson, 1968). Anaemia is common in patients with ulcerative colitis and haematological studies have shown that blood loss and malabsorption of iron are the major factors in its production (Ormerod, (1968). By the measurement of the fall in total body radioactivity after the parenteral administration of ${ }^{59} \mathrm{Fe}$, Stack, Smith, Jones, and Fletcher 1969) showed that the amount of blood lost per rectum in 17 patients with idiopathic proctocolitis is related to the activity of the disease, as judged by the sigmoidoscopic appearance of the rectal mucosa, and the extent of the disease, as judged by barium enema examination. They also found that a rectal loss of 50 to $150 \mathrm{ml}$ of blood a week was common, even when the patient saw no blood in the faeces and the rectal mucosa did not appear haemorrhagic on sigmoidoscopy.

Rectal bleeding may be the most obvious feature of ulcerative colitis, and apart from producing anaemia, usually causes the patient considerable alarm. Conventional medical treatment, although aimed at the prompt termination of an acute attack, includes no measures intended specifically to stop rectal bleeding.

Nevertheless, there is some evidence to suggest that excessive fibrinolysis at the rectal mucosal Received for publication 29 October 1969.

'Present address: Cumberland Infirmary, Carlisle. level might contribute in some way to the patho- $\overrightarrow{\overrightarrow{0}}$ genesis of ulcerative colitis. Kwaan, Cocco, and 3 Mendeloff (1964), in a study of the localization of plasminogen activator in rectal mucosa, showed that in five out of six patients with active ulcer-ce ative colitis there was an abnormally high concentration of plasminogen activator at the site of the crypt abscesses, whereas in eight patients with quiescent colitis the distribution of plasminogen activator in the rectal mucosa conformed to the normal vascular fibrinolytic pattern. Also Nilsson, Anderson, and Björkman $\frac{D}{0}$ (1966), in an account of their clinical experiences with epsilon-aminocaproic acid (EACA), de- $\widetilde{N}$ scribed seven patients with ulcerative colitis in N whom rectal bleeding continued despite conven- N tional therapy. The fibrinolytic activity of the peripheral venous blood was not increased in any of these patients, yet EACA controlled the bleeding in all. Unfortunately, side effects in the form $\stackrel{\Phi}{\oplus}$ of nausea and diarrhoea, whether the EACA was given orally or intravenously, made it impossible to continue with this form of treatment. These $\mathbb{\otimes}$ observations, together with the findings of Cox, $\frac{\mathbb{1}}{\mathbb{D}}$ Poller, and Thomson (1967) that excessive gastric $\varrho$ fibrinolytic activity may play a role in the pathogenesis of gastric ulceration, prompted an inves- $\delta$ tigation into the role of fibrinolysis in ulcerative colitis, the results of which will be reported elsewhere. Part of the project was designed to assess $\rightleftharpoons$ the efficacy of EACA in the control of rectal 


\begin{tabular}{|c|c|c|c|c|c|c|c|}
\hline Patient & $\begin{array}{l}\text { Age } \\
\text { (years) }\end{array}$ & Sex & $\begin{array}{l}\text { Total } \\
\text { Duration } \\
\text { of } \\
\text { Disease }\end{array}$ & $\begin{array}{l}\text { Extent } \\
\text { of } \\
\text { Disease } \\
\text { Process }\end{array}$ & $\begin{array}{l}\text { Average } \\
\text { Bowel } \\
\text { Frequency } \\
\text { (per 24 } \\
\text { hours) }\end{array}$ & $\begin{array}{l}\text { Associated } \\
\text { Treatment }\end{array}$ & $\begin{array}{l}\text { Sigmoidoscopic } \\
\text { Grading }^{1}\end{array}$ \\
\hline 1 & 69 & $\mathbf{F}$ & 3 years & Left $^{2}$ & 6 & None & Moderate \\
\hline 2 & 15 & $\mathbf{M}$ & 1 year & Rectum & 3 & $\begin{array}{l}\text { Sulphasalazine } \\
(0.5 \mathrm{~g} \mathrm{tds})\end{array}$ & Moderate \\
\hline 3 & 18 & $\mathbf{F}$ & $1 \frac{1}{2}$ years & Rectum & 6 & $\begin{array}{l}\text { Sulphasalazine } \\
\text { (1.0 g tds) }\end{array}$ & Moderate \\
\hline 4 & 73 & $\mathbf{M}$ & 1 year & Left & 12 & None & Moderate \\
\hline 5 & 44 & $\mathbf{M}$ & $\frac{1}{2}$ year & Left & 8 & None & Severe \\
\hline 6 & 34 & $\mathbf{M}$ & $2 \frac{1}{2}$ years & Rectum & 2 & $\begin{array}{l}\text { Sulphasalazine } \\
(1.0 \mathrm{~g} \text { tds })\end{array}$ & Moderate \\
\hline 7 & 43 & $\mathbf{M}$ & $1 \frac{1}{2}$ years & Rectum & 8 & $\begin{array}{l}\text { Sulphasalazine } \\
(1.0 \mathrm{~g} \text { tds }) \\
\text { Prednisolone } \\
\text { enema nocte }\end{array}$ & Moderate \\
\hline 8 & 51 & $\mathbf{F}$ & 10 years & Rectum & 10 & None & Severe \\
\hline 9 & 51 & $\mathbf{F}$ & 4 years & Left & 6 & None & Severe \\
\hline 10 & 14 & $\mathbf{M}$ & 6 weeks & Left & 6 & None & Severe \\
\hline 11 & 64 & $\mathbf{M}$ & 20 years & Rectum & 8 & None & Severe \\
\hline
\end{tabular}

Table I Details of patients studied

${ }^{1}$ Mild, moderate, or severe according to the classification of Goligher et al (1968).

'2'Left' indicates that the descending and sigmoid colon is involved as well as the rectum.

\begin{tabular}{|c|c|c|c|c|c|}
\hline Patient & $\begin{array}{l}\text { Haemoglobin } \\
(\mathrm{g} / 100 \mathrm{ml})\end{array}$ & $\begin{array}{l}\text { Euglobulin } \\
\text { Lysis Time } \\
\text { (before } \\
\text { EACA } \\
\text { therapy) }\end{array}$ & $\begin{array}{l}\text { Euglobulin } \\
\text { Lysis Time } \\
\text { (seventh day } \\
\text { of treatment) }\end{array}$ & Effects & Side Effects \\
\hline 1 & $10 \cdot 7$ & $6 \cdot 66$ & $3 \cdot 33$ & $\begin{array}{l}\text { Bleeding cleared } \\
\text { within } 48 \text { hours }\end{array}$ & None \\
\hline $\begin{array}{l}\mathbf{2} \\
\mathbf{3}\end{array}$ & $\begin{array}{l}10.9 \\
11.0\end{array}$ & $\begin{array}{l}5 \cdot 55 \\
8 \cdot 33\end{array}$ & $\begin{array}{l}1 \cdot 0 \\
3 \cdot 33\end{array}$ & $\begin{array}{l}\text { No effect on bleeding } \\
\text { No effect on bleeding }\end{array}$ & $\begin{array}{l}\text { None } \\
\text { Nausea }\end{array}$ \\
\hline 4 & 10.5 & $4 \cdot 76$ & 1.0 & $\begin{array}{l}\text { Bleeding cleared } \\
\text { within } 48 \text { hours }\end{array}$ & None \\
\hline 5 & 11.9 & 1.0 & 1.0 & $\begin{array}{l}\text { Bleeding cleared } \\
\text { within } 48 \text { hours }\end{array}$ & None \\
\hline 6 & 10.7 & 6.66 & $3 \cdot 33$ & $\begin{array}{l}\text { Bleeding less but not } \\
\text { completely cleared }\end{array}$ & $\begin{array}{l}\text { Slight } \\
\text { nausea and } \\
\text { giddiness }\end{array}$ \\
\hline 7 & $11 \cdot 7$ & - & - & $\begin{array}{l}\text { Bleeding less but not } \\
\text { completely cleared }\end{array}$ & None \\
\hline 8 & $11 \cdot 7$ & - & - & $\begin{array}{l}\text { Bleeding cleared } \\
\text { within } 48 \text { hours }\end{array}$ & Nausea \\
\hline 9 & $9 \cdot 0$ & - & - & $\begin{array}{l}\text { EACA discontinued afte } \\
\text { because of severe nausea } \\
\text { vomiting }\end{array}$ & $\begin{array}{l}\text { r } 48 \text { hours } \\
\text { and }\end{array}$ \\
\hline 10 & $11 \cdot 8$ & - & - & $\begin{array}{l}\text { Bleeding cleared } \\
\text { within } 48 \text { hours }\end{array}$ & $\begin{array}{l}\text { Nausea and } \\
\text { vomiting }\end{array}$ \\
\hline 11 & $11 \cdot 5$ & - & - & $\begin{array}{l}\text { Bleeding cleared } \\
\text { within } 48 \text { hours }\end{array}$ & None \\
\hline
\end{tabular}

Table II Results

${ }^{1}$ The euglobulin lysis is expressed as arbitrary units obtained by multiplying the reciprocal of time in minutes by 1,000 (Sherry et al, 1959).

bleeding in patients with ulcerative colitis in whom this was a prominent feature. The results form the basis of this report.

\section{Patients and Methods}

Eleven outpatients took part in this study, the diagnosis of ulcerative colitis being made on the basis of clinical features and the sigmoidoscopic appearance of the rectal mucosa. The extent of the disease process was assessed by barium enema examination. All the patients fulfilled the following criteria: (1) Despite associated diarrhoea, rectal bleeding was the most pronounced symptom, being clearly visible at each bowel action. (2) There was no significant change in the symptomatology for at least two weeks before the start of EACA therapy. (3) The patients were either receiving no therapy at the time of the EACA trial, or if treatment had been previously instituted this had not been altered for the preceding two weeks and was continued unchanged during the period of EACA administration.

The age of the patients ranged from 14 to 73 years and these data, together with the details as to the duration, extent, frequency of bowel action, sigmoidoscopic grading, and associated therapy, are summarized in Table I.

All the patients were seen before the EACA trial when the clinical features and sigmoidoscopic appearance of the rectal mucosa were recorded. The latter was graded as normal, mild, moderate, or severe according to the classification of Goligher et al (1968). Peripheral venous blood samples were taken for haemoglobin estimation in all and for assessment of the euglobulin lysis time in six, the method of Chakrabarti, Bielawiec, Evans, and Fearnley (1968) being used. This gives a normal range for euglobulin lysis of approximately 60 to 300 minutes or 3 to 16 arbitrary units, this figure being derived by multiplying the reciprocal of the time in minutes by 1,000 (Sherry, Lindemeyer, Fletcher, and Alkjaersig, 1959).

The patients were then given a supply of EACA syrup sufficient for a seven-day course at a dose of $6 \mathrm{~g}$ four times daily and were asked to report back on the seventh day of treatment, having carefully observed during the preceding six days whether there was any change in the severity of the diarrhoea and rectal bleeding and whether they had noticed any other effects of treatment. At this visit the symptoms and results of sigmoidoscopy were again recorded and the euglobulin lysis time of the peripheral venous blood was reestimated in six patients. The EACA treatment was discontinued and appropriate alterations were made to the therapeutic regime if required.

\section{Results}

The results are summarized in Table II. All of the patients were anaemic before the EACA trial.

Six patients reported that rectal bleeding had cleared within 48 hours of starting the therapy and remained absent for the remainder of the course of treatment. Also there was no immediate recurrence of bleeding after stopping EACA therapy. Two patients reported a considerable reduction in rectal blood loss and two patients noted no significant change. One patient found 
it necessary to discontinue the EACA treatment after 48 hours because of the severity of side effects.

\section{EUGLOBULIN LYSIS}

No increase in the fibrinolytic activity of the peripheral venous blood was demonstrated in the six patients in whom the euglobulin lysis time was estimated. The repeat euglobulin lysis time estimated on the seventh day of therapy showed a considerable reduction but not a complete absehce of fibrinolytic activity of the peripheral venous blood, except in case 5 where the value before treatment was also low.

\section{SIDE EFFECTS}

Six patients reported no side effects and four patients complained of various combinations of nausea, vomiting, and giddiness but were nevertheless able to complete the course of treatment. One patient complained of such severe nausea and faintness that it was necessary to discontinue the treatment after 48 hours. None of the patients noticed any increase in the frequency of bowel action and no thrombotic episodes occurred during the course of treatment.

\section{Discussion}

These results confirm those of Nilsson et al (1966) and show that antifibrinolytic therapy with EACA is an extremely effective method of controlling rectal bleeding in certain patients with ulcerative colitis, despite the fact that the pretreatment fibrinolytic activity of the peripheral venous blood was not increased.

In all seven patients studied by Nilsson et al (1966) the EACA, whether given orally or intravenously, had to be discontinued because of the severity of side effects, these being predominantly nausea and diarrhoea. In the patients constituting the present series the average frequency of bowel action per 24 hours was unaffected by EACA therapy, although five certainly found nausea troublesome, one so much so that the treatment had to be discontinued. The reason for this difference is difficult to understand as the daily dose of oral EACA used in this study ( $24 \mathrm{~g}$ ) was not significantly different from that of Nilsson et al (1966).

It is possible that as an alternative to EACA another antifibrinolytic drug may become available which has less troublesome side effects. Also, the possibility of local EACA therapy in the form of retention enemata is worth considering.
In the patients who failed to respond, the disease process was confined to the rectum and rectosigmoid regions. This was a disappointing finding as haemorrhage is often a feature of $\subseteq$

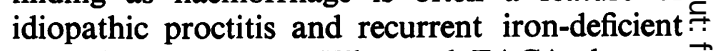
anaemia is common. Why oral EACA therapy $\overrightarrow{\vec{F}}$ should have been so ineffective in this group is again difficult to explain.

The fact that the euglobulin lysis time before $\frac{\bar{m}}{\mathrm{~m}}$ treatment was begun was within the normal $\overrightarrow{\widetilde{D}}$ range in five of the six patients studied, and also the observation that although rectal bleeding was $\infty$ quickly abolished there was still some demon- $\overrightarrow{0}$ strable fibrinolytic activity in the peripheral $\vec{\overrightarrow{ }}$ venous blood, suggests that the bleeding may be ${ }_{\sigma}^{\vec{\omega}}$ caused at least in part by a local release of plas-o

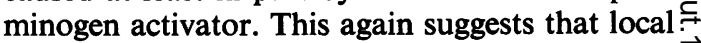
EACA treatment might be expected to be bene- $\overrightarrow{.}$ ficial and this form of therapy is surely worth a of trial.

It must be emphasized that this study was in no way intended to be a full clinical trial and no attempt was made to quantitate the rectal blood $\vec{c}$ loss, the effect of therapy being judged solely by observation of the patient. Despite these limitations $\vec{\varphi}$ the results are sufficiently impressive to merit the consideration of EACA therapy in any case of ulcerative colitis where rectal bleeding is a predominant feature.

This work forms part of a dissertation to be submitted by one of us (R.H.S.) for the M.D. degree of the University of London.

\section{References}

Chakrabarti, R., Bielawiec, M., Evans, J. F., and Fearnley, G. R. (1968). Methodological study and a recommended tech-o nique for determining the euglobulin lysis time. J. clin. Path., 21, 698-701.

Cox, H. T., Poller, L., and Thomson, J. M. (1967). Gastric음 fibrinolysis. A possible aetiological link with peptic ulcer. Lancet, 1, 1300-1302.

Goligher, J. C., Dombal, F. T. de, Watts, J. McK., and Watkinsin, G. (1968). Ulcerative Colitis. Baillière, Tindall, and N Cassell, London.

Kwaan, H. C., Cocco, A., and Mendeloff, A. I. (1964). Histologic W demonstration of plasminogen activation in rectal biopsies $\sigma$ from patients with active ulcerative colitis. J. Lab. clin. Med., 64, 877.

Nilsson, I. M., Anderson, L., and Björkman, S. E. (1966). Epsilonaminocaproic acid (E-ACA) as a therapeutic agent based $\varrho$ on 5 years' clinical experience. Acta med. scand., 180," Suppl., 448 .

Ormerod, T. P. (1968). Anaemia in ulcerative colitis. Proc. roy. $\bar{O}$ Soc. Med., 61, 931.

Sherry, S., Lindemeyer, R. I., Fletcher, A. P., and Alkjaersig, N. (1959). Studies on enhanced fibrinolytic activity in man. J. clin. Invest., 38, 810-822.

Stack, B. H. R., Smith, T., Jones, J. H., and Fletcher, J. (1969) Blood and iron loss in colitis. Proc. roy. Soc. Med., 62, 497. 